\title{
Facile synthesis of hypercrosslinked resins via chloromethylation and continuous condensation of simple aryl molecules
}

\author{
XIAOYAN ZHANG, QIU JIN, LIBO DAI and SIGUO YUAN* \\ School of Chemical Engineering and Energy, Zhengzhou University, Zhengzhou 450001, P.R. China
}

MS received 11 January 2010; revised 17 March 2010

\begin{abstract}
A sort of non-polystyrene type hypercrosslinked resin was firstly synthesized through chloromethylation of simple aryl molecules (benzene, toluene, naphthalene, diphenyl), succedent continuous Friedel-Crafts alkylation polymerization and post-crosslinking reaction. The chemical and porous structures of these novel resins were characterized with BET, FT-IR and elementary analysis, respectively. The results showed that these novel adsorptive materials possessing abundant crosslinked networks had high specific surface areas (up to $1191.26 \mathrm{~m}^{2} / \mathrm{g}$ ), large pore volumes $(0 \cdot 2-1.4 \mathrm{ml} / \mathrm{g}$ ), narrow pore size distributions (mainly in the range of micropores and small mesopores).
\end{abstract}

Keywords. Non-polystyrene; hypercrosslinked resins; aryl monomer; synthesis.

\section{Introduction}

Owing to excellent adsorption, separation, catalysis and storage performances for various small organic molecules, the synthesis of porous polymer matrix has attracted increasing attention (Li et al 2002; Wang et al 2006; Wood et al 2008). So far, two main methodologies could be used for the preparation of these porous materials: (i) the suspension polymerization of co-monomer mixture with the presence of porogen or diluents (Sherrington 1998); (ii) the post-crosslinking reaction of styrene or styrene-divinylbenzene (ST or ST-DVB) polymer in solution or a highly swollen state (Tsyurupa and Davankov 2006). However, the above methodologies present various disadvantages such as the humdrum polymeric matrices (usually ST-DVB matrix), nonuniform pore size or crosslinked network distributions, and fussy synthetic processes.

Herein, we firstly reported a facile preparation of porous resins via chloromethylation and continuous condensation of simple aryl molecules, and their chemical and porous structure were also characterized.

\section{Experimental}

The synthesis of the novel non-polystyrene type porous resins could be mainly classified into three approaches: (i) chloromethylation of aryl monomer and following self-polymerization; (ii) chloromethylation of aryl monomer and following mutual-polymerization with other aryl

*Author for correspondence (yuansiguo2005@yahoo.com.cn) monomers; and (iii) further post-crosslinking reaction of the above resins. The synthetic scheme and reaction conditions were given in scheme 1 , table 1 and particular synthetic samples.

\subsection{The synthesis of resin DP-CME (synthesis approach 1)}

Diphenyl (DP, 2.0176 g, $13 \mathrm{mmol}$ ), chloromethyl methyl ether (CME, $2.5 \mathrm{ml}, 33 \mathrm{mmol}), \mathrm{ZnCl}_{2}(1.1530 \mathrm{~g})$ and nitrobenzene $(10 \mathrm{ml})$ were added to a $50 \mathrm{ml}$ flask equipped with the reflux condenser and anhydrous $\mathrm{CaCl}_{2}$ tube. After stirring at room temperature for 5-10 $\mathrm{min}$, the chloromethylation reaction was carried out at $45^{\circ} \mathrm{C}$ for $4 \mathrm{~h}$. After that, added $\mathrm{ZnCl}_{2}(0.5770 \mathrm{~g}, 4 \mathrm{mmol})$ to the system, the polymerization was carried out at $80^{\circ} \mathrm{C}$ for $12 \mathrm{~h}$.

The resulting polymer monolith was crushed, washed with hot deionized water, and extracted with acetone in a Soxhlet apparatus. The product was dried under vacuum to give $2.3907 \mathrm{~g}$ of DP-CME resin (theory: $2 \cdot 3320 \mathrm{~g}$ ). Elementary analysis: C: $86 \cdot 56 \%$; H: $5 \cdot 20 \%$; FT-IR (KBr, $\mathrm{cm}^{-1}$ ): 3015.21 (Ar-H stretch); 2908.97 (aliphatic C-H stretch); $1605 \cdot 45$ and $1482 \cdot 86$ (conjugated $\mathrm{C}=\mathrm{C}$ ).

\subsection{The synthesis of resin $B-C M E-B$ (synthesis approach 2)}

Benzene (B, $2 \mathrm{ml}, 22.5 \mathrm{mmol})$, CME (5.2 ml, $68.2 \mathrm{mmol})$, $\mathrm{ZnCl}_{2}(1.0052 \mathrm{~g})$ and nitrobenzene $(10 \mathrm{ml})$ were added to a $50 \mathrm{ml}$ flask equipped with the reflux condenser and anhydrous $\mathrm{CaCl}_{2}$ tube. After stirring at room temperature 
a

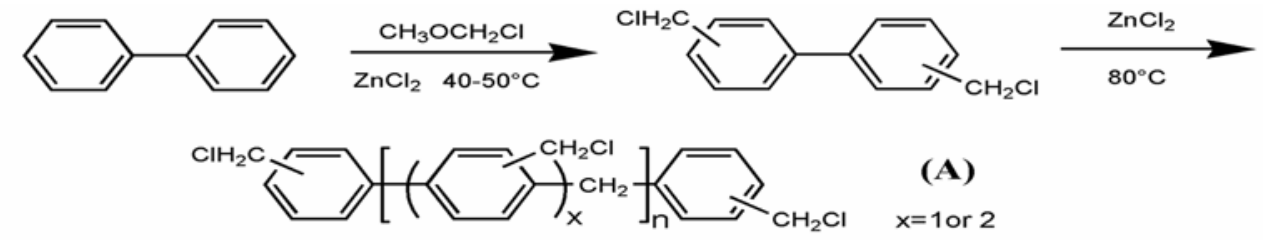

b
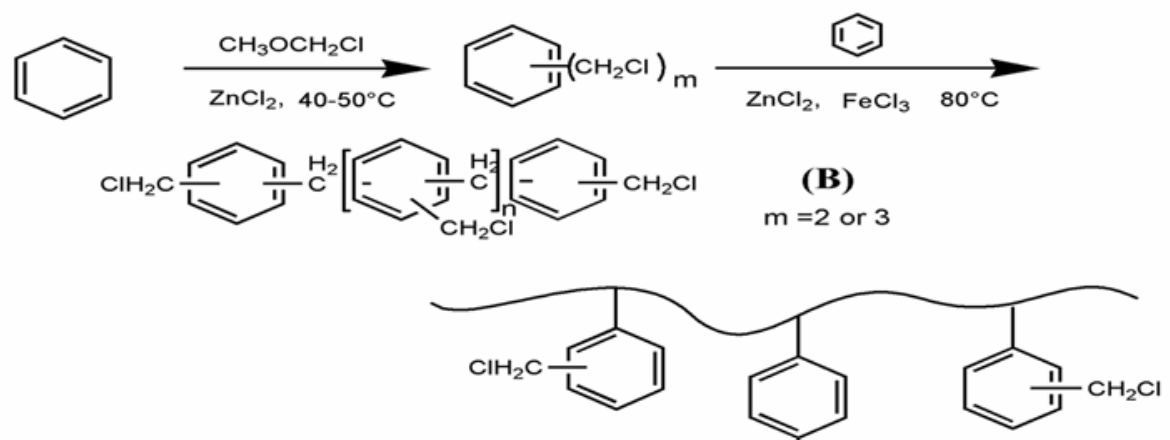

(A) or (B)
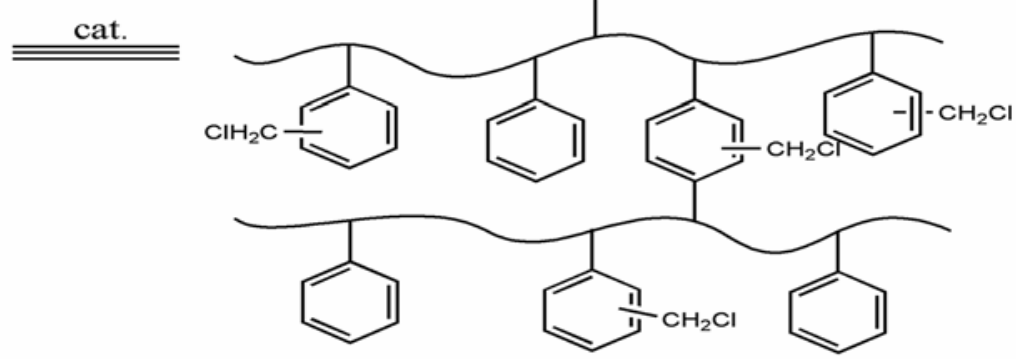

Scheme 1. Typical synthetic process of the two main resins.

for 5-10 $\mathrm{min}$, the chloromethylation reaction was then carried out at $45^{\circ} \mathrm{C}$ for $12 \mathrm{~h}$. After that, added B ( $1 \mathrm{ml}$, $11.2 \mathrm{mmol})$ and $\mathrm{FeCl}_{3}(0.3179 \mathrm{~g}, 2 \mathrm{mmol})$ to the reaction system, the polymerization was carried out at $80^{\circ} \mathrm{C}$ for $12 \mathrm{~h}$.

After the resulting polymer monolith was treated as described in the synthesis approach 1, B-CME-B resin $(3.2789 \mathrm{~g})$ was given (theory: $3 \cdot 1656 \mathrm{~g})$. Elementary analysis: C: $83.60 \%$; H: $5.70 \%$; FT-IR $\left(\mathrm{KBr}, \mathrm{cm}^{-1}\right)$ : 3002.95 (Ar-H stretch); 2913.05 (aliphatic C-H stretch); $1601 \cdot 36$ and $1495 \cdot 12$ (conjugated $\mathrm{C}=\mathrm{C}$ ).

\subsection{The post-crosslinking reaction (synthesis approach 3)}

Swollen $0.6959 \mathrm{~g}$ dry resin B-CME-B in $10 \mathrm{ml} \mathrm{1,2-}$ dichloroethane for $24 \mathrm{~h}$, then $0.0749 \mathrm{~g} \mathrm{FeCl}_{3}$ was added. The reaction was carried out in a $50 \mathrm{ml}$ flask equipped with the reflux condenser and anhydrous $\mathrm{CaCl}_{2}$, at $60^{\circ} \mathrm{C}$ for $4 \mathrm{~h} 80^{\circ} \mathrm{C}$ for another $4 \mathrm{~h}$.

After the product was treated as described in the synthesis approach $1,0.6374 \mathrm{~g}$ the post-crosslinking resin, named as p1 (B-CME-B) resin, was given.

The chemical and porous structures of resin DP-CME, $\mathrm{B}-\mathrm{CME}-\mathrm{B}$ and their post-crosslinking products were evaluated with IR elementary analysis and the dynamic sorption and desorption of $\mathrm{N}_{2}$ (BET). The experimental results are summarized in tables 1 and 2 ; figures 1 and 2.

\section{Results and discussion}

After chloromethylation and alkylation polymerization, the specific surface area (SSA) of DP-CME, B-CME-B, TO-CME and NA-CME resin could attain $469.32 \mathrm{~m}^{2} / \mathrm{g}$, $310 \cdot 19 \mathrm{~m}^{2} / \mathrm{g}, 615.83 \mathrm{~m}^{2} / \mathrm{g}$ and $366.81 \mathrm{~m}^{2} / \mathrm{g}$, respectively. And the BET results further identified: these non-styrene adsorptive resins have typical structural characteristics of hypercrosslinked resin, such as narrow pore size distribution, abundant micro and meso pores (see figure 1). But, there were $-\mathrm{CH}_{2} \mathrm{Cl}$ peak at $1258-1260 \mathrm{~cm}^{-1}$ in the IR spectra, and elementary analysis showed the total content of $\mathrm{C}$ and $\mathrm{H}$ for DP-CME and B-CME-B resins were only $91.85 \%$ and $89.3 \%$, respectively (see figure 2 and table 2). Moreover, the weight of some resins obtained in the synthesis process were higher than the theoretical yield. All these results demonstrated that there were some residual chloromethyl groups in B-CME-B and DP-CME matrix. Perhaps, this could be due to decrease in chloromethyl reactivity with increase of crosslinking density 
Table 1. Reaction condition and the specific surface area (SSA) results.

\begin{tabular}{|c|c|c|c|c|c|c|}
\hline Resins & Monomer (1) & Monomer (2) & $\begin{array}{l}\text { Molar ratio } \\
(1):(3)^{*} \text { or } \\
(1):(3):(2)\end{array}$ & Solvent & $\begin{array}{l}\text { Reaction } \\
\text { condition }\end{array}$ & $\begin{array}{c}\text { SSA } \\
\left(\mathrm{M}^{2} / \mathrm{G}\right)\end{array}$ \\
\hline DP-CME & & & $1: 2 \cdot 5$ & Nitrobenzene & $40(4 h)+80(12 h)$ & $469 \cdot 32$ \\
\hline TO-CME & & & $1: 2$ & Dichloroethane & $40(5 h)+80(15 h)$ & $615 \cdot 83$ \\
\hline B-CME-B & & & $1: 3: 0 \cdot 5$ & Nitrobenzene & $40(8 h)+80(12 h)$ & $310 \cdot 19$ \\
\hline NA-CME & & & $2: 4: 1$ & Dichloroethane & $40(5 h)+65(17 h)$ & $366 \cdot 81$ \\
\hline
\end{tabular}

*The monomer (3) in all the reactions was chloromethyl methyl ether.
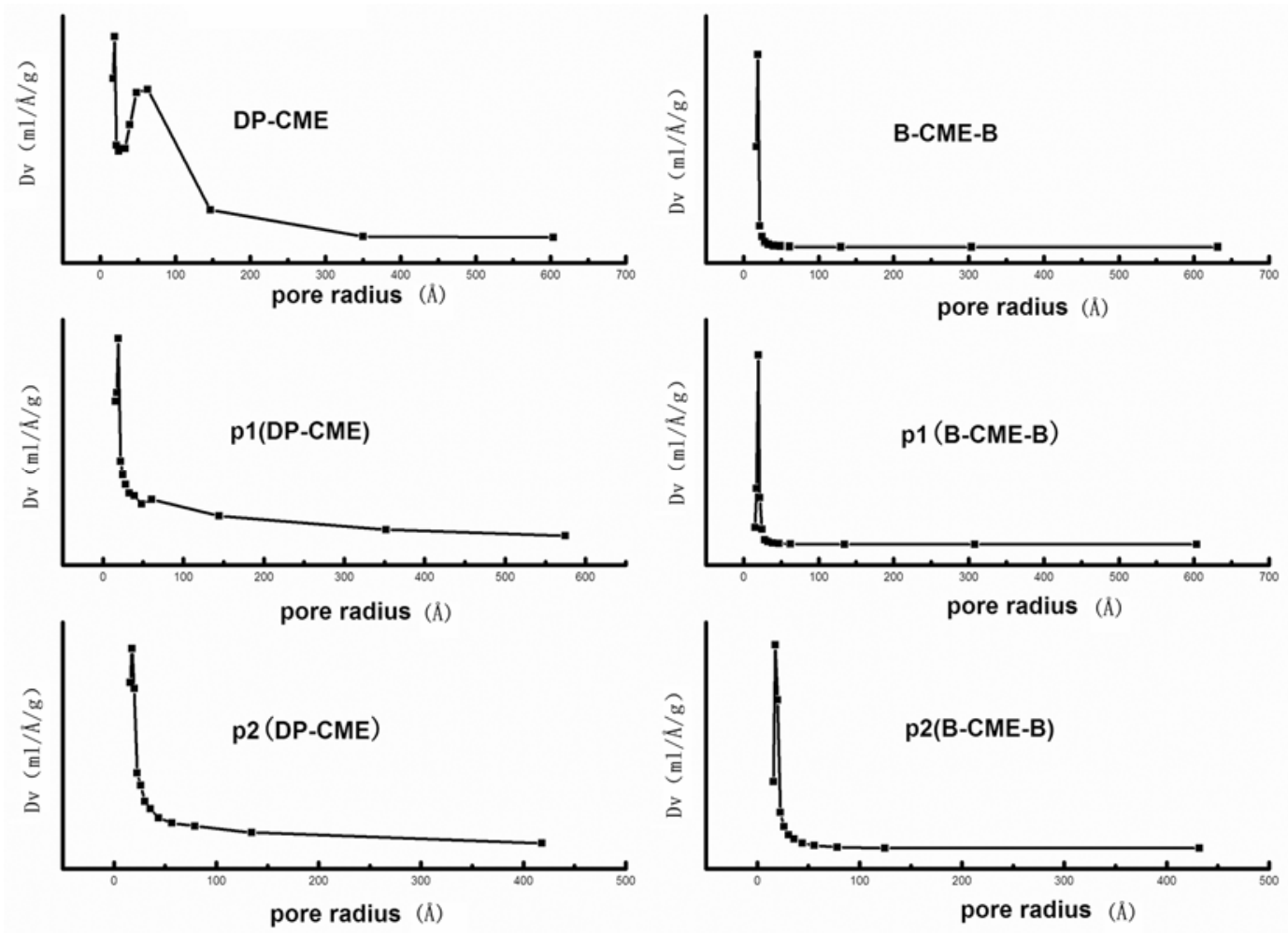

Figure 1. The pore size distribution of the resins DP-CME, B-CME-B and their multi-postcrosslinking products.

when the polymerization was carried out in the presence of an excess dichloromethyl monomer ratio.

As an important intermediate, the chloromethylated resin (chlorine-sphere) had been widely applied to the synthesis of various reactive and functional polymers. On continuing our efforts, the further chemical modification (such as amination, etherification, thio-etherification) of the porous resins containing chloromethyl groups was in progress.

To further improve the porous structure of above polymer matrix, a multi-crosslinking process was also adopted in this paper. The experimental results showed that the SSAs of DP-CME and B-CME-B resins were increased from the original $469.32 \mathrm{~m}^{2} / \mathrm{g}$ and $310 \cdot 19 \mathrm{~m}^{2} / \mathrm{g}$ to $801.58 \mathrm{~m}^{2} / \mathrm{g}$ (p1(DP-CME)) and $715.91 \mathrm{~m}^{2} / \mathrm{g}$ (p1(BCME-B)) when these resins were heated at $70^{\circ} \mathrm{C}$ for $8 \mathrm{~h}$ in the dichloroethane solution of $\mathrm{FeCl}_{3}$. And when the crosslinking process was carried out for another $4 \mathrm{~h}$ at the same conditions, the SSAs of above resins could be further increased to $1191.26 \mathrm{~m}^{2} / \mathrm{g}$ (p2(DP-CME)) and $1175.54 \mathrm{~m}^{2} / \mathrm{g}$ (p2(B-CME-B)). Meanwhile, the $\mathrm{C}$ and $\mathrm{H}$ total content of resins DP-CME, B-CME-B had also raised to $94.96 \%$ and $92.73 \%$ (see table 2), the IR adsorption peak of chloromethyl group at $1258-1260 \mathrm{~cm}^{-1}$ were not so strong than the original products, and the stretching vibration peak of $\mathrm{C}-\mathrm{Cl}$ at $698-700 \mathrm{~cm}^{-1}$ were almost 
Table 2. The results of the multi-postcrosslinking reaction.

\begin{tabular}{lcccc}
\hline Resin & SSA $\left(\mathrm{m}^{2} / \mathrm{g}\right)$ & $\begin{array}{c}\text { Average pore } \\
\text { radius }(\AA)\end{array}$ & $\begin{array}{c}\text { Total pore } \\
\text { volume }(\mathrm{ml} / \mathrm{g})\end{array}$ & $\begin{array}{c}\text { Elementary analysis } \\
\text { (total content of C and H) }(\%)\end{array}$ \\
\hline DP-CME & 452.51 & 30.39 & 0.6876 & 91.85 \\
p1(DP-CME) & 801.58 & 27.18 & 1.089 & - \\
p2(DP-CME) & 1191.26 & 24.85 & 1.480 & 94.96 \\
B-CME-B & $310 \cdot 19$ & 16.56 & 0.2568 & 89.3 \\
p1(B-CME-B) & 715.91 & 17.44 & 0.6243 & - \\
p2(B-CME-B) & 1175.54 & 19.43 & 1.142 & 92.73 \\
\hline
\end{tabular}
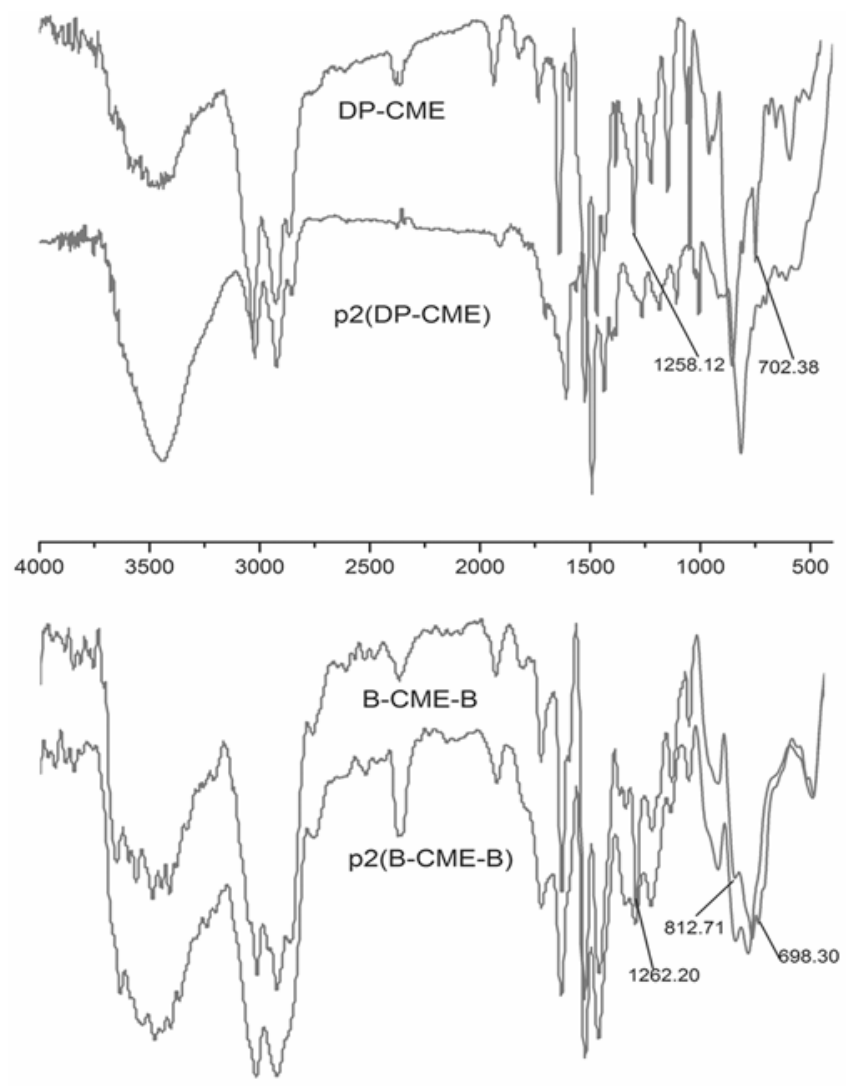

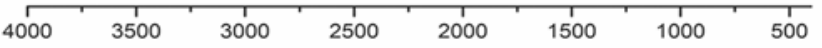

Figure 2. The IR spectra of non-hypercrosslinked resins DP$\mathrm{CME}, \mathrm{B}-\mathrm{CME}-\mathrm{B}$ and their post-crosslinking products $\mathrm{p}$ (DPCME), p2(B-CME-B)

disappear. These experimental data imply that a new hypercrosslinked network was developed in above postcrosslinking reaction.

As the polymer matrix containing massive phenyl rings possessed abundant micro and meso pores, we thought they may have excellent adsorptive properties for the non-polar organic molecules such as benzene and toluene. It primarily demonstrated that the adsorption capacity of $\mathrm{B}-\mathrm{CME}-\mathrm{B}$ resin for benzene was $145 \mathrm{mg} / \mathrm{g}$ in the benzene solution $(521 \mathrm{mg} / \mathrm{l})$. And further work was in progress.

\section{Conclusions}

As an important intermediate, the chloromethylated resins (chlorine-sphere) DP-CME, B-CME-B, TO-CME and NA-CME were synthesized through the following two approaches: (i) chloromethylation of aryl monomer and following self-polymerization; (ii) chloromethylation of aryl monomer and following mutural-polymerization with other aryl monomers. To further improve the porous structure of above polymer matrices, a multi-crosslinking process was also adopted in this paper, and two kinds of high SSAs resins p2(DP-CME) $\left(1191.26 \mathrm{~m}^{2} / \mathrm{g}\right)$ and $\mathrm{p} 2(\mathrm{~B}-$ CME-B) $\left(1175.54 \mathrm{~m}^{2} / \mathrm{g}\right)$ were synthesized.

\section{Acknowledgement}

The authors are grateful for the support of the National Natural Science Foundation of China (No. 20574063).

\section{References}

Li, Aimin et al 2002 Chemosphere 47981

Sherrington D C 1998 Chem. Commun. 2275

Tsyurupa M P and Davankov V A 2006 React. \& Funct. Polym. 66768

Wang Jingping, Fei Zhenghao and Tang Shuhe 2006 Chin. J. React. Polym. 1452

Wood, C D, Tan B, Trewin A, Su F, Rosseinsky M J, Bradshaw D, Sun Y, Zhou L and Cooper A I 2008 Adv. Mater. 20 1916 